Notre Dame Journal of Formal Logic Volume XV, Number 2, April 1974 NDJFAM

\title{
PROFESSOR QUINE AND REAL CLASSES
}

\author{
JAMES K. FEIBLEMAN
}

Symbolic logic was committed by its founders to the theory of real classes, but nominalism, which at the time prevailed in other philosophical enterprises, soon reasserted itself in logic. The result was that the theory of real classes was difficult to maintain. This difficulty is best exemplified by the work of Professor Quine, and I propose to show it. Quine early on had the advantage of study with Whitehead, the realist, but it was not easy for a thinker trained in the tradition of nominalism to hold to the recognition of the reality of classes, since such a concept is the very contradictory of the nominalistic notion of their unreality. Frege had signalled a change from the nominalistic tradition in a return to realism, but Russell and Whitehead working together had difficulty in holding to it. Professor Quine's early work therefore is nominalistic despite the influence on him of the realism of his teacher, Whitehead.

As perhaps we should expect in a book which bears an acknowledgement of discussions with Carnap and which carries an introduction by Whitehead, the question of whether classes are real is somewhat muddy. ${ }^{1}$ It could be argued of course that any signs which name anything except material individuals are abstract and to this extent mark an independent domain, in the Platonic sense, thus committing symbolic logic to metaphysical realism. But my concern here is with a more special and explicit involvement. Nothing of the sort is to be found in A System of Logistic.

In that early work the reality of classes seems to be assumed but then we find also the conventional principle of extensionality adopted, ${ }^{2}$ and a principle which leaves no doubt that the reality resides in members but not in classes. That was in 1934. By 1941 things have cleared up a bit and the reality of classes seems to have asserted itself in Quine's thinking. One has to match the principle of extensionality against the postulation of the

1. A System of Logistic, Harvard University Press, Cambridge, Massachusetts (1934), pp. vii and ix.

2. Ibid., pp. 32 and 106. 
reality of variables which "may represent terms of any kind ... whether concrete existents, propositions, or classes." 3 That was in 1934. By 1941,

When we say that men are numerous, we mean neither that every man is numerous nor even that some men are numerous; what is numerous is rather a certain abstract entity, the class of men. ${ }^{4}$

Leaving aside the question of how a class rather than its members can be said to be numerous, it is obvious that here at least Quine took classes to be genuine entities, "abstract entities," as genuine, evidently, as their members.

By 1950 "the adoption of class variables of quantification" meant that

the price paid for this increased power is ontological: objects of a special and abstract kind, viz., classes, are now presupposed. ${ }^{5}$

Definite enough. But a few lines later Quine repeated a statement he had made a few pages earlier, that "To be assumed as an entity is to be assumed as a value of a variable." Are the two statements consistent?

There is another and more fundamental problem evident here. For if "to be is to be the value of a variable," then how is the variable to be? The only possible answer is that it is not; there is only non-being for the variable. We are left with the curious situation of living with the real values of unreal variables. Variables without being present an odd and embarrassing situation at best for those of us, including Quine, who deal so commonly with variables. Quine never did explain how this was possible, how, for example, we are able to deal so efficiently with and refer so accurately to real values when all that we have at hand are unreal variables. If classes are ontological objects of a special and abstract kind, then how can being be confined to the values of a variable? Presumably only if the values of the variable are classes. But what if they are individuals? And in either case what are we to say of the ontological status of the variables themselves?

There was certainly a vigorous nominalism implicit (when not explicit) in the influence of Carnap, to which Quine was highly susceptible, and there was also the professed nominalism of his frequent collaborator, Goodman. Goodman undertook to establish a philosophy on the basis of the assumption

3. Ibid., p. 10. Italics mine.

4. Elementary Logic, Ginn \& Co., Boston (1941), Section 56.

5. Methods of Logic, Henry Holt, New York (1950), p. 228.

6. On p. 224 it was a simpler version, "To be is to be a value of a variable." These two statements are retained in the 1959 revised edition of the book. The statement is evidently a favorite of Quine's for it is repeated, later again in slightly altered form: "To be assumed as an entity is, purely and simply, to be reckoned as the value of a variable." From a Logical Point of View, Harvard University Press, Cambridge, Massachusetts (1953), p. 13. 
that there is in the world nothing but (material) individuals. ${ }^{7}$ But the assumption itself is self-contradictory for it relies upon the existence of at least one real class, namely the class of (material) individuals. So the world must contain at least one class. The principle by which nominalists are guided, explicitly or implicitly, is that of Ocham's Razor, entia non sunt multiplicandum praeter necessitatem, entities must not be multiplied beyond necessity. Now Ocham's Razor is a solid principle and one which can be sustained, but only on the assumption that it is one of a pair of principles the other of which for want of a better name might be called "Kant's Shaving Bowl." The principle as stated by Kant is, Entium varietates non temere esse minuendas, ${ }^{8}$ or, the variety of entities should not be rashly diminished. Quine is guilty of the latter in the case of variables.

The particular sort of "Platonic ontology of universals" "which Whitehead (and others in recent centuries) have maintained has I suspect, been somewhat misunderstood by Professor Quine. He understood well enough in 1941 that the 'class' of Principia Mathematica is "an abstract entity, a universal, even if it happens to be a class of concrete things," ${ }^{10}$ but it is my impression that he thought it impossible to accept the reality of universals as independent of material individuals and at the same time accept also the equal reality of those material individuals. Yet there is nothing contradictory in the two notions. Most of the time Plato did not do so, but the modern philosophers, like Peirce for instance, who came down on this side, did,

There was a reason, then, why, beginning in 1941 Quine felt that he could not go all the way with the Platonic ontology. But he could still see the germ of a viable doctrine in it, and so his subsequent work has been the history of his attempts to return to realism. The attempts were not entirely successful; but because they were not entirely unsuccessful, either, they remain immensely suggestive.

I recognize of course that Quine's concern in the remaining books I propose to examine was not metaphysics but logic. I cannot emphasize too strongly that I am not competent to criticize Professor Quine's logic nor even to know whether it is in need of criticism. Quine does logic, I do metaphysics, and in this case, to be more specific, the metaphysics of logic. Therefore what I propose to commit him to could conceivably seem to him either inadvertent or irrelevant, or even plain wrong. In both the former instances I could still be right, and in the last my thesis could still be open to argument. But in the interest of isolating the assumptions of symbolic logic, the case I have made out seems a necessary contribution. As we shall presently see, in his Word and Object Quine undertook a

7. Nelson Goodman, The Structure of Appearance, Harvard University Press, Cambridge, Massachusetts (1951).

8. Critique of Pure Reason, A, 656; B, 684 .

9. Selected Logic Papers, Random House, New York (1966), pp. 18-19.

10. Ibid., p. 21 . 
position consistent with realism, a position which he had emphatically repudiated earlier, for instance in From A Logical Point of View. I cannot imagine that he would want to thank me for pointing this out, if I am right; or grant me the courtesies of a disputant who shares with him a devotion to the disinterested pursuit of truth, if I am wrong. ${ }^{11}$ My aim therefore is more modest. It is to show how symbolic logic can waver in exploring the theorems based on its implicit assumptions, which do not always agree with its explicitly stated axioms.

We find early in Quine's work a disposition to interpret logical problems in terms of linguistic analysis. By reference to such devices as syncategorematicity he proposed in a paper published in 1939 to "transform ontological questions, in this superficial way [sic], into linguistic questions."12 The borderline between names and syncategorematic expressions falls on variables. Quine gives as an example that to say that "pebbles have roundness" does not entitle us to say that "pebbles have something," roundness not being "something" but merely a syncategorematic expression." Names, then, are merely "those constant expressions which replace variables and are replaced by variables according to the usual laws of quantification.",14

I am always suspicious of a plea for the usefulness of "convenient fictions,"15 and my suspicions are confirmed at the end of the book where Quine came to what seems to me to be a realistic conclusion entirely unsuited to the entire foregoing nominalistic argument. For the language of logic the only ontology required consists in concrete individuals, classes of such individuals, and classes of such classes. ${ }^{16}$ As both a realist and a Platonist I feel compelled to agree, though somewhat dizzily from the turnaround. As a Platonist I am delighted with the hierarchy of classes and as a realist I am delighted with the reality of concrete individuals. I had been led to expect the latter but not the former, for surely Quine did not mean an

11. Consider for example the treatment meted out to his imaginary adversary Wyman. "Wyman, by the way, is one of those philosophers who have united in ruining the good old word 'exist'." Quine repudiates Wyman's "bloated universe." Wyman is not allowed to argue but is attacked personally: e.g., "Wyman, in an ill-conceived effort to appear agreeable...." "Wyman's overpopulated universe... offends the aesthetic sense." "Wyman's slum of possibles is a breeding ground for disorderly elements." Finally, Quine refers to "the rank luxuriance of Wyman's universe of possibles." All in "On What There is," From a Logical Point of View, pp. 3-4.

12. The Way of Paradox, Random House, New York (1966), p. 64.

13. Ibid., p. 65 .

14. Ibid., p. 66 .

15. Ibid., pp. 66-67.

16. Ibid., p. 68 . 
ontology of real concrete individuals and unreal classes and unreal classes of classes!

For Frege all words are names. It is a long way from this kind of realism to the suspicions about the references of words which Quine seems to have maintained as early as 1951. Quine in fact advanced two arguments against the reality of names.

In the first argument, not all words are names for him, for "many are admissible in significant sentences without claiming to name; witness 'the" and 'of',"' etc. ${ }^{17}$ In another place I have tried to show that 'the' is the name of particularity and 'of' the name of possession. Whatever has particularity and possession has material existence; for whatever possesses them affects other things accordingly.

Quine's second argument was to the effect that naming can be false, and he gives as his examples black swans and mountains 8800 meters high. ${ }^{18}$ No doubt the names of these things are not the names of material things, and to the extent that they purport to be they are misleading. He has indeed demonstrated that some names are false, but that some names are false does not prove that all names are false or even that most names are false. There can be false naming but that does not prove that naming as such is false. There is such a thing as incorrect naming, but the successes of mathematics and of the experimental sciences have been made possible by correct naming. If it were always the case that "names are a red herring" 19 we would have been hard put to it to proceed as well as we have not only in such exact fields as logic and physics but even in our practical dealings by means of our ordinary languages.

In 1953, Quine seems to have been of the opinion that classes were not real but merely convenient summaries of the similarities of members of classes. That is the classic view of nominalism, in a tradition in which 'classes' were called 'universals.' The work to which I have reference is the one providing a new set of foundations for mathematical logic. ${ }^{20}$ In the following year Quine had not changed his mind, for he then asserted that the ' $\varepsilon$ ' of class membership entails the ' $=$ ' of equality, the former making the latter dispensable. ${ }^{21}$ This is nominalism with a vengeance for it assumes that there is nothing to classes but their members.

Some variety of Platonism is unavoidable in symbolic logic because that logic requires classes, and no method of reduction has been found that can eliminate them. Even when they are declared non grata they are still

17. Ibid., p. 127 .

18. Ibid., p. 128.

19. Ibid.

20. From a Logical Point of View, pp. 80-101

21. Selected Logic Papers, p. 46. 
treated as though they were honored persons. And there is still no gain in dancing all round the admission in an effort to get along only with material individuals. The question of the reality of classes is not clarified but only confused by shifting the argument to the question of whether there is a totality of classes or a paucity of classes. ${ }^{22}$ The essential question is whether such classes as must be admitted are conventional in the sense of being a way of talking about the similarity of real individuals or about general thoughts or are authentic items in the inventory of the world. No doubt the 1947 Quine of Goodman and Quine ${ }^{23}$ was a nominalist, and the shift to conceptualism was only a struggle, and an unsuccessful one, to escape from that position. ${ }^{24}$

What Quine did there was to reduce the Principia Mathematica to what he considered its bare essentials. The twofold division into inclusion, in the extensive or material sense that $\alpha$ is included in $\beta$ if every member of $\alpha$ is a member of $\beta$, and abstraction, which gives the rule for the formation of classes that there is a class $\hat{x}$ characterized by a given condition if there are objects each of which satisfies the condition, will serve as well as the threefold foundation based on membership, alternative denial and universal quantification. ${ }^{25}$

Such a foundation assumes that there are no real classes, in the sense that intension is not to be taken seriously in logic. Classes may certainly be taken as the extensions of a property, as indeed they are in the now conventional principle of extensionality for classes which Quine accepted, but an intensional logic is possible, the intension of a class being the properties which it possesses in itself apart from its members or its subclasses.

In other essays in the same volume, Quine made it clear that he admired nominalism with respect to classes, ${ }^{26}$ and the acceptance of conventionalism was explicit enough. There are a number of passages in the work which bear this out without equivocation. "To be assumed as an entity," Quine wrote again, but more emphatically this time, "is, purely and simply, to be reckoned as the value of a variable."27 One might well ask again then how is the variable to be? He goes on, "The totality of our so-called knowledge or beliefs ... even of pure mathematics and logic, is a man-made fabric." 28 Could any statement of conventionalism be more

22. From a Logical Point of View, pp. 127-129.

23. Nelson Goodman and W. V. Quine, "Steps toward a constructive nominalism," in The Journal of Symbolic Logic, vol. 12 (1947), pp. 105-122.

24. From a Logical Point of View, p. 129.

25. From a Logical Point of View, particularly pp. 85-94. See also a much earlier paper, published in 1937 and reprinted as Chapter VII of Selected Logic Papers.

26. From a Logical Point of View, Chapter VI.

27. Ibid., p. 13.

28. Ibid., p. 42. 
explicit than this? Conventionalism of course is a form of nominalism. ${ }^{29}$ In addition we have the agreement with Carnap: "Consider the question whether to countenance classes as entities. . . Carnap has maintained that this is a question not of matters of fact but of choosing a convenient language form. .. With this I agree. . .,30

There can be little doubt that the powerful pull of linguistic analysis did conscript Quine for a while at least, and may have left a permanent mark. In 1954, he found himself able to assert that "the sense of externality has its roots, if our speculations are right, in the intersubjectivity which is so essential to the learning of a language.",31

By 1960, in Word and Object Quine seems to have had quite a different opinion and opted for the reality of classes, something approaching the view of realism or Platonism. He had been inclining that way whenever he thought of the needs of mathematics ${ }^{32}$ and he would continue to, ${ }^{33}$ but the conviction that classes could not be interpreted nominalistically but had to be considered real abstract objects was certainly growing. It grew through reconsiderations of the import of quantification theory ${ }^{34}$ but also in more direct ways, despite his rather plaintive disclaimer that he had never held any other opinion. ${ }^{35}$ At least one of his other critics also has found him inconsistent in this book, ${ }^{36}$ especially with respect to the reality of classes. ${ }^{37}$

In accepting what, I insist, was a new "ontic commitment" for Quine, he rather gagged a little at certain extreme instances, at "ideal objects" for example, such as "mass points, frictionless surfaces.", It would not be too difficult to find many more examples in modern physics, such as absolute vacua, infinite speeds, perfectly radiating black bodies, etc. These, he said, are "limit myths" such as delight "literary critics, psychoanalysts, and philosophers of religion." But why are these more

29. William Kneale and Martha Kneale, The Development of Logic, Clarendon Press, Oxford (1962), p. 644 .

30. From a Logical Point of View, p. 45.

31. Reprinted in The Ways of Paradox, p. 221.

32. Word and Object, Technology Press of Massachusetts Institute of Technology, Cambridge, Massachusetts (1960), pp. 267, 269.

33. Ontological Relativity and Other Essays, Columbia University Press, New York (1969), p. 102.

34. Word and Object, pp. 232, 242, 243 n. 5 .

35. Ibid., p. 243 n. 5 .

36. Erik Stenius, "Beginning with Ordinary Things," in Donald Davidson and Jaakko Hintikka (Ed.), Words and Objections, D. Reidel, Dordrecht, Holland (1969), p. 27.

37. Ibid., p. 51.

38. Ibid., p. 249. 
difficult to accept than electrons, baryons and leptons? Whatever fills a gap in experimental physics may be presumed to exist.

The older philosophical language for "classes" was as we have noted earlier, "universals." Although Peirce was himself a declared realist, he wrote somewhere on the vexed question of nominalism versus realism that nobody in his right mind would insist that all universals are real, only that some are, and the determination of which universals are real is the business of the experimental sciences. By means of experiments it is possible to verify 'leucocytes' and to falsify 'leprechauns.' There is experimental evidence that the ideal limits are not myths but scientifically-endorsed classes.

Quine's decision was to retain his belief in the reality of classes, despite the difficulties, and because of their flexible role in relations and the theory of numbers. ${ }^{39}$ Indeed in a sort of final summary he declared that he saw no need for any entities except physical objects and abstract classes in order to account for the objects in the universe. ${ }^{40}$ No Platonic realist could say any more. And he even overcame his own repugnance at "ideal objects" when he considered that Einstein's theory of relativity had been accepted not for its specific material references but on its own ground as an abstract theory in relation to other contending theories. ${ }^{41}$ And if at the end of Word and Object he made a passing laudatory reference to the kind of reduction of logic to language which Frege had cautioned against and Wittgenstein's followers had endorsed as the only true course in philosophy, ${ }^{42}$ it must be remembered that this was not his overall or prevailing view. That he was still not clear where the line is to be drawn is obvious in the passage. The "ascent" is not "semantic" as Quine called it but logical, a movement to propositions higher in type.

Quine has often been guilty of conventionalism in confusing logical necessity with linguistic expression. He criticized logic for employing extra-logical references in its examples, as physics does not do. But he made the same mistake he accused Wittgenstein of making. He accused Wittgenstein of refusing the ascent by holding to examples and refusing to generalize about them, while not recognizing that this is just what logic does do when it moves from its examples (i.e., Quine's "extralogical terms" $)^{43}$ to propositions of greater generality. The struggle for objectivity in relation to abstract objects is not without its lost skirmishes in Quine's work, though the eventual outcome of victory in the battle may be obvious. The witness of what I might call occasional nominalistic back-

39. Word and Object, p. 266

40. Ibid., p. 267.

41. Ibid., p. 272 .

42. Ibid., p. 273-274.

43. Ibid., p. 273. 
sliding was still evident in 1960. How else interpret a paper entitled "Variables Explained Away?",44

A man's treatment of names in logic is a pretty good index to his metaphysics. Linguistic analysis, like its cousin, logical positivism, is of course frankly nominalistic. Quine's early treatment of names was in this direction. With the question of names as with that of classes, $1960 \mathrm{sig}-$ nalled a turn for Professor Quine. Early on, as we saw, he not only defended the reality of values of variables against the reality of variables, but he also challenged the process of naming, holding that names were syncategorematic. Then in 1960 we were told both that "singular terms, other than variables, ... might suggestively be called names" ${ }^{45}$ and that "variables alone remain as singular terms." 46 Which, one is tempted to wonder, is it, singular terms other than variables or variables alone? Clearly, a change has been called for even if a settlement has not been reached.

The vacillation between early Russell and the reality of classes and later Goodman and the nominalistic thesis is evident in Mathematical Logic. $^{47}$ The argument in favor of real classes is there put in pragmatic terms: we deal with classes as though they were real. ${ }^{48}$ The pragmatic argument while never a conclusive one is still very strong, especially when persisting as long as this one has. Classes as abstract entities are a necessary part of our subject matter. Later on in the same work, however, urder the rubric of identity we get what amounts to the conventional nominalistic assumption, for we are told that "classes are the same when their members are the same." ${ }^{49}$ Imagine a golf club and a yacht club with exactly the same members. Would that mean that a yacht club is a golf club? Brick houses and piles of bricks might have exactly the same number and size of bricks, but brick houses are not piles of bricks.

Nominalism is the theory that only material individuals are real; idealism (of the objective variety) is the theory that only classes are real. The nominalistic view of classes is that they are mere aggregates or summaries of individuals. The idealistic view of individuals is that they are classes having themselves as their own sole members. In the effort to avoid the pitfall of nominalism, Quine may have fallen into the error of idealism..$^{50}$

44. Selected Logic Papers, pp. 227-235.

45. Word and Object, p. 180.

46. Ibid., p. 186.

47. Revised edition of Mathematical Logic, Harvard University Press, Cambridge, Massachusetts (1965).

48. Ibid., p. 121.

49. Ibid., pp. 134-135.

50. Ibid., p. 135. 
The contention of idealism as well as of realism that there are real classes can be sustained only on the basis of the existence of real individuals. A real individual is not merely a class having itself as its sole member. Socrates is a man but he is also a philosopher, and not all men are philosophers; similarly, he is also a husband, a father, and a tax-payer; but not all men are fathers and husbands, and not all men meet their lawful fiscal obligations. In short, an individual may be a member of a class but he is not only a member of a class; indeed there is reason to suspect that the material individual is not merely even the sum of its classes. ${ }^{51}$

The problem of what constitutes the member of a class is a difficult one for the logician but it is tied in with the problem of what constitutes a class, and probably neither can be solved apart from the other.

The attempts to solve the problem of individuals have been prominent ones in modern logic but thus far the results are less than satisfactory. I offer a few examples.

In line with the traditional logic of the syllogism, in order to satisfy the condition that something exists it is necessary only to deny its non-existence, in short, "to deny that there are none." rather than an existential proposition. It says logically that it is false that $x$ does not exist, which is not the equivalent of $(\exists x)$. But this is ambiguous no matter whether the reference is to a pronoun or to a specific material individual. It is satisfied by either of the following statements

(1) $(\exists x)$ ( $x$ is an individual)

(2) Richard M. Nixon exists

Is it satisfied by the following statement also?

(3) $(\exists x)(x=$ Winston S. Churchill)

Logic is concerned with the formal relations of a materially existing individual but not with whether the individual actually does exist (did exist, will exist). Did individuals ever exist, will they exist? What is the nature of their existence now if they do exist? Logic could not care less. Just what are the material individuals or the concrete objects to which logic refers? Quine saw the difficulty but did not undertake to solve it. ${ }^{53}$

Logic is concerned with individual existence only in so far as for example in the propositional calculus there have to be the contraries and contradictories of universals, and in the calculus of classes there have to be the members of classes. The problem is seen in all of its difficulties in PM, *14, in the well-known theory of descriptions. Everyone knows by now that it is impossible to specify an individual in any language in such a way

51. See e.g., my Foundations of Empiricism, Nijhoff, The Hague (1962), pp. 61-62.

52. Mathematical Logic, p. 101.

53. Ibid., p. 122 . 
that no ambiguity or confusion is admissible, except of course by specific naming. The proper name is the only way. But language is incurably general and most of its sentences are not composed chiefly of proper names. Logic does well to begin with axioms intuitively discovered, for any attempt to get it off the ground by framing indisputable categories and statements is sure to be theoretical only. Wittgenstein outlined this method in the Tractatus, but there it resembles the method employed in experimental science and not the one employed in formal logic.

The connection between existence as conveyed by $(\exists x)$ and the assertion that there is one and only one object $x$, in the expression $(7 x)$ has never been made clear so far as I know. Both assert existence, and the distinction seems to be between 'at least one. . ' and 'one and only one...' In the latter case, known since PM in the theory of descriptions, the attempt to pin down a single item in existence with a tag suitable for logical uses has been only more or less successful. Quine's handling of the problem consists in reconstructing the proper name as an abstract. ${ }^{54}$ This treatment might satisfy logic but only at the expense of misrepresenting existence. For the assumption that the proper name is to be an abstract means to make of it a class with a finite number of members. ${ }^{55}$ But that is hardly a satisfactory solution unless in logic we are prepared to disregard the conditions of existence.

The proper understanding of the material individual as not exhausted by its class-membership, or even by its class-memberships, holds the key to the understanding of the ontological status of real classes. In the shift from the reference of colloquial languages to the reference of purely for malized languages something got lost, and that something is the reference itself. Perhaps in pure mathematics this is an occupational condition essential for productivity, but in logic, at least, it makes for serious dislocations.

An additional difficulty, and perhaps the supreme one, in dealing with the problem of individual existence in logic arises from the failure to dis tinguish between the formal and the material modes of being. The formal mode is what Plato called "Ideas" or forms and what has been called since the Middle Ages "universals." (It has already been accepted by Quine on those occasions when he declared for the reality of classes.) The material mode is what Aristotle meant by "primary substance" and what we mean by matter (and/or energy) in motion is space and time.

The device of the distinction enables us to account for the being of what existed in the past but no longer exists, and of what could exist in the future but does not yet exist; both states of being exclude non-being and have been traditionally described by the term 'possibility,' as opposed to 'actuality' or existence. Thus if we reserve the word 'is' for that special

54. Ibid., p. 149.

55. Cf. Ibid., pp. 132 and 151. 
mode of being we call possibility, and 'existence' for that other kind of being we call actuality, all eventualities are provided for, and we are in a position to deny Quine's contention that "to say that something does not exist, or that there is something which is not, is clearly a contradiction in terms." ${ }^{56}$ The contradiction is dissipated when we consider that the italicized 'is' does not mean the same in both places. In the first place it means possibility and refers to the formal mode, and in the second place it means actuality and refers to the material mode.

Certainly in his book on Set Theory and Its Logic ${ }^{57}$ Quine wavered on the question of the reality of classes. He began the work with his theory of "virtual classes," and while "espousing no nominalistic sort of philosophy" ${ }^{\prime 8}$ seems to have committed himself to one. The object seems to have been to gain all the advantages of using classes while at the same time not admitting them as real. ${ }^{59}$ "Virtual classes" means "defining ' $\varepsilon$ ' jointly with the form of notation ' $\{x: F x\}$ ' of class abstraction, which purports to designate 'the class of all objects $x$ such that $F x \ldots$ ' The whole combination $y \varepsilon\{x: F x\} \ldots$ reduces . . . to $F y$, so that there remains no hint of there being such a thing as the class $\{x: F x\} . "$ "60 Then when "admitting classes as real ' $\varepsilon$ ' is no longer considered a mere fragment of a compound ' $y \varepsilon\{x: F x\}$ '; for we need ' $y \varepsilon z$ ' also, with quantifiable ' $z$ '.",61

But it is a little difficult to see how merely by means of notational shorthand we have got rid of real classes. If ' $y \varepsilon\{x: F x\}$ ' reduces to $F y$ then the class membership-and hence the class-is still there concealed behind the brief drapery. But in any case as we have seen real classes are restored (or added) explicitly.

Much in this theory depends upon a distinction between classes, variables and members. If we say that the members we are talking about are for the moment limited to classes and with individuals excluded, then the distinction fails. Variables may have values which are classes, but what distinguishes a variable from a class? The attempt to employ virtual classes in place of real classes, while later admitting real classes would seem to be peremptory.

The trouble arises perhaps because of the assumption that classes always mean classes in extension. If this were the case, then all my special pleading is wasted as irrelevant. But for the metaphysical theory of classes, and not only for computational purposes, classes must be

56. Ibid., p. 150. Italics his.

57. First Edition, Set Theory and Its Logic, Belknap Press of Harvard University Press, Cambridge, Massachusetts (1963).

58. Ibid., p. 9.

59. Ibid., p. 20.

60. Ibid., p. 16.

61. Ibid., p. 29. 
thought of also in intension. And when we think of them in intension then not only what logicians ordinarily call classes are classes but also what they call quantifiers and what they call constants or truth-functional signs and what they call variables, all these are classes as well. Quine at the outset of his book on class theory admits the difficulty of defining classes. But in my sense this is not difficult at all, for a class is a universal term designating an abstract entity which may or may not have corresponding exemplifications.

By 1969 Quine found himself again committed to the theory of real classes though still quite uncomfortable with it. In an essay on "Natural Kinds" ${ }^{\prime 62}$ he was again unable to go the whole way with realism. Although he found the sense of similarity basic ${ }^{63}$ it was also "logically repugnant",64 and "disreputable.",65 Basic, yes; but why repugnant and disreputable? Certainly not to a realist, only to one whose early discipline had been nominalistic. These are strange descriptions of a view which is about to be accepted!

But the difficulty is easy to pick out. Quine seems to have thought that we "sort things into kinds" "66 but we do not, not that is unless we are nominalists, because that is a subjective view which implies that things did not belong to kinds until we sorted them out in that way. A realist would say not that we sort things into kinds but that we acknowledge the existence of kinds when we recognize things. This is how we learn to use a name; the resemblance we rely upon is not between words but between material things. Consider for example the difficulty that Quine had with the fact that "objects in just that shade of red can come in all sorts of shapes, weights, sizes and smells." 67 In so far as they may all be red, they are similar, but note carefully that it is the objects which are similar and not the red, for the red is not similar but identical in all the different objects.

Russell as well as Quine after him seems to have found "similarity" basic. Russell admitted that he could get rid of all universals except the universal of similarity. ${ }^{68}$ Quine found the idea logically repugnant and disreputable probably because he thought of classes chiefly in extension. Why, one could well ask him with a reference to the same essay, did he refuse intension to classes but admit it to properties? ${ }^{69}$ In the lengthy

62. Ontological Relativity and Other Essays, pp. 114-138.

63. Ibid., p. 116.

64. Ibid., p. 117.

65. Ibid., p. 133.

66. Ibid., p. 116.

67. Ibid., p. 120.

68. Bertrand Russell, An Inquiry into Meaning and Truth, G. Allen and Unwin, London (1940), p. 127.

69. Ontological Relativity and Other Essays, p. 118. 
example he gave of the quality of a middle shade of red, he seems to have been more concerned with its difference than with its similarities to other instances of the same shade. ${ }^{70}$ Yet what counts in a quality is not the relatedness but the intrinsicness; not the fact that the same shade of red, say, in two different objects, have more in common with each other than they have differences from other things, but the fact that they have instant vividity of an immediately recognizable sort.

The core of the difficulty is the problem of the definition of similarity. Quine, throughout the last mentioned essay, sought in vain for a definition that would satisfy him and found none. No wonder that his excellent sense of order was disturbed and he sought in such terms as "repugnant" and "disreputable" to express his distaste.

The difficulty can be cleared up with a definition and a corollary characterization of identity. The definition of similarity can be stated in terms of an identity of parts. Two things are similar if they have one or more identical parts. The idea is not an easy one for the nominalist to accept, but I submit that two instances of a shade of red, regardless of whether it is part of a flag in one case and of a flower in another, is not two but one. With respect to the redness alone (and it was that after all that we were talking about) there are no differences which would authorize us to talk in terms of similarity. The word we want is 'identity': red is red and we do not need two names for it. The differences between flag and flower will not justify 'similarity': they are not parts of red. It is part of them but only in terms of relatedness, not in terms of quality, and red is a quality.

What I have been saying about a quality could be claimed equally for a form. Anything triangular in shape is identical with respect to that shape with anything else triangular.

Nominalists have difficulty in conceiving of the many genuine and valid appearances of an identity. They do not find it easy to accept the idea of one thing with many appearances. In representing the relation if we put ' $x$ ' for 'red,' and then encounter 'red' again and again put ' $x$,' we should soon see that ' $x=x$ ' was a way of bringing them together, and from their appearances they obviously belonged together. But, I submit, ' $x=x$ ' is not a relation, for there are not two terms but only one term repeated once.

In this sense the class has not many members but only one member repeated a given number of times, as many times in fact as there are members. The class is the same for the identity of appearances of the property which defines the class.

No one has taken sufficient ontological congnizance of the fact that we recognize a class when we name an individual by means of a common noun. We have the habit of calling an individual by its classname. "Look at that dog," we say, using only the common noun. Knowing the name it answers to and calling it by that name, say "Rover," is something else. We name

70. Ibid., p. 120 . 
an individual uniquely by means of a proper noun. But the class is not the common noun and the individual is not the proper noun, these are only names. Objects and the names of objects are often confused, particularly in the former case. The name of a class, say 'six' and the class are thought to be one and the same, when they are not.

To the question, "what objects does a theory require?" Quine proposed the answer, "those objects that have to be values of variables for the theory to be true." ${ }^{71}$ Values of variables again. Only this time the importance of the variables seems to have returned to the picture, For there may be no objects, only a universe of discourse. ${ }^{72}$ Evidently, now the names which occur in a theory are real and not merely the things named. Moreover, there can be "nameless objects,", testifying to the importance of names, the name in this case being 'objects.' Quine, it seems to me, here made the mistake of assuming that all nameless objects shared with named objects the property of being already recognized by natural kinds. ${ }^{74}$ But the cosmic universe is an exceedingly large one, and the probabilities from its size and variety are that there are more unrecognized natural kinds than recognized ones. And if this is the case, then it serves as an additional argument for the reality of classes, to the one which consists in the fact that we cannot recognize objects until we can name them (i.e., identify their natural kinds), that there already are classes whose names as yet are unknown.

The story of Professor Quine's work in logic is on one side at least the story of his efforts to recognize the Platonic reality of classes and names, after the manner of Frege and the influence of Frege in Whitehead and Russell's Principia Mathematica. It looked for a while as though this might be the case and as though the influence of the nominalism of Professor Goodman might be overcome despite the unexpected assistance from the Wittgenstein school of linguistic analysis. But lately he has been struck down from another quarter, and language is uppermost again in his logic theory. Apparently Quine believes that language primes logic. He got himself out from under the influence of Goodman only to fall a victim to that of Professor Chomsky. In a recent monograph on the Philosophy of Logic ${ }^{75}$ he has written, "I see logic as the resultant of two components, truth and grammar.",76

On the topic of truth, the ontological distinction between propositions, which belong to logic, and facts, which belong to the material world, is dif -

\footnotetext{
71. Ibid., p. 96.

72. Ibid.

73. Ibid., pp. 65-66.

74. Ibid., p. 65 .

75. Philosophy of Logic, Prentice-Hall, Englewood Cliffs, New Jersey (1970).

76. Ibid., p. xi.
} 
ficult to maintain if the correspondence theory of truth be rejected, as it has been by Quine, for reasons which, it seems to me, complicate the picture unduly. Between the logical proposition and the material situation there are two "intangible intervening elements, a meaning and a fact" "77 which make of the correspondence theory "a hollow mockery." Just so; for here is the arrangement which Quine insists on. There is the proposition, say "Snow is white"; then there is the meaning of the proposition, namely, that snow is white; in addition, and from underneath, so to speak, there is the fact that snow is white; and there is the material situation which consists in what the fact describes, namely that snow is white; thus:

"Snow is white" (sentence);

'Snow is white' (proposition);

Snow is white (the meaning of the proposition);

Snow is white (a fact);

Snow is white (that to which the fact refers).

But can we distinguish between the proposition and its meaning in this way? The sentence, perhaps, and the meaning are different, but not the proposition, for the proposition is its meaning, and that meaning is what the sentence conveys. On the lower end, that snow is white is a fact of material existence, and it allows no wedge to be driven between fact and existence in order to repeat the assertion once again.

In the new book Quine's work on set theory plays a heavy part. Set theory is excluded from logic explicitly ${ }^{73}$ but discussed at length, and after all classes are very close, for a set is a class that has only classes as members. ${ }^{79}$ The existence of a class with individuals as members characterizes the class. "Sets are those classes which are members of other classes.",80

A metaphysician professionally concerned with accounting for the world in all of its aspects would have to weigh heavily the place of the representation of material individuals in any logic. Thus for him classes count for more than sets. If sets belong to that vast domain of classes of classes which is pyramided over the lowest class whose members are material individuals, then they are covered by classes other than the class of material individuals.

But Quine's attack on classes began with an attack on sets. He was building toward a theory of "virtual classes" but started with a theory of

77. Ibid., p. 1.

78. Ibid., p. 64 .

79. Ibid., p. 71.

80. R. Feys and F. B. Fitch, Dictionary of Symbols of Mathematical Logic, NorthHolland Publishing Co., Amsterdam (1969), 82.1. 
"sham sets.", The device employed in both cases is "contextual definition," getting rid of sets and classes by means of contextual devices, "to simulate the apparatus of set theory on the basis of an object language lacking that apparatus."

No doubt contextual devices can be employed to get rid of classes by simulation. But if the simulation is genuine, then it is an as-if situation, and the classes are virtually real. When classes have classes as members up in the hierarchy of classes, it is without reference to individuals, and the classes might better be described as virtually real, as real, say, as virtual set theory which is without reference to individuals.

Names fare no better than real classes in Quine's latest work. First of all, he thinks of names as singular terms only, a serious limitation on the theory of names, ${ }^{82}$ but then we learn that "being in the lexicon does not, of course, mean being a name." 83 This statement is considered so important it is repeated twice on the same page. "Lexicon," like "vocabulary" is Professor Quine's linguistic equivalent of what the logicians and mathematicians are accustomed to calling undefined terms and axiom-sets. Professor Quine "denies that predicates are names." 84 To the thesis of Frege he seems to offer a contradictory proposal, namely, that there are no words in logic which are names. Attributes, we are told in the same place, which belong to "the universe of objects which are the values of our variables of quantification" are not names. The arbitrary reservation of names to singular terms, which is what we seem to have here, may merely represent a semantic difficulty. Real classes, i.e., universals, are also named. Attributes belong to these classes.

The intent in the cases both of classes and of names is still clear. It is to banish universals and to get along with the language of individuals, of objects and their properties, in terms not of logic but of grammar. The distinction between language and logic is blurred by the assumption that logic is after all only a special sort of grammar. More confusion than clarification results from attending to similarities as though they were crucial when differences are just as crucial and perhaps in some instances more so. Even if we admit that logic is only a special sort of language, we are still puzzled by the question of what sort of language it is. What is special about the logical language that requires us to treat it as fundamental? If the study of logic is the study of assumptions which are fundamental to all other studies, then this is peculiar to logic. There is only one set of foundations, whereas there are many languages. How could we assert that English is fundamental in the same way, or French? We have not yet succeeded in paring logic to its essentials, which seems to be the admirable

81. Philosophy of Logic, p. 69.

82. Ibid., p. 26.

83. Ibid., p. 27.

84. Ibid., p. 28. 
aim of Professor Quine, by translating all of its problems into the language of grammar and syntax. Getting rid of real classes remains for the nominalistically inclined an unattained goal.

One has the persistent conviction that the logician who is too heavily influenced by the philosophers of ordinary language, by Wittgenstein and by Carnap, never quite comes to grips with either the real world of material individuals or that other real world of abstract entities but remains forever in a limbo of representation, of signs which stand between us and what they signify and of words which prevent us from making contact with their objects. Wittgensteinhad an insight when he discovered that it was necessary to attend to language in order to prevent it from interfering with communication, but it is just possible that in the end he, like so many of his followers, fell a victim to the very danger which he had meant to warn everyone against. I cannot help wondering whether Quine is not to be numbered among the victims.

Tulane University

New Orleans, Lousiana 